\title{
Quando a "Avamunha" não bate: o conflito como aspecto estruturante do Candomblé em Portugal ${ }^{2}$
}

\author{
When "Avamunha" doesn't play: conflict as a structural \\ aspect of Candomblé in Portugal
}

\section{João Ferreira Dias}

Portugal. Instituto Universitário de Lisboa, Centro de Estudos Internacionais Doutorado em Estudos Africanos. Mestre em História e Cultura das Religiões. ID ORCID: https://orcid.org/0000-0001-9056-8510. E-mail:joaoferreiradias@outlook.pt.

\section{Resumo:}

A transnacionalização do Candomblé para Portugal acarretou um processo de ressignificação religiosa que vem sendo enfatizado pela literatura antropológica dedicada ao tema. Não obstante a força da plasticidade e da criatividade na reconfiguração e adaptação do Candomblé em terras lusas, um fenômeno não menos significativo é o conflito, que será tratado neste artigo como estruturante do campo religioso candomblecista português, cujas dinâmicas revelam a existência de alianças feitas e refeitas, com base em critérios de nacionalidade e sexualidade e demandas do mercado religioso.

Palavras-chave: Candomblé, Portugal, Conflito, Mercado Religioso.

\footnotetext{
Toque chamado, também, de arrebate, do fon hamwnya, é utilizado para abrir as celebrações, trazer os Orixás paramentados ao salão festivo ("barracão"), encaminhar os Orixás para o fim do transe, e encerrar as cerimónias.

2 Apesar da adaptação fonética e gráfica das palavras, bem como da estrutural gramatical, ao português do Brasil, o presente artigo foi escrito a partir de um código linguístico luso, que creio em nada lesar a cadência do argumento apresentado.
}

Recebido em 10 de novembro de 2019 Avaliador A: 17 de janeiro de 2020 Avaliador B: 15 de fevereiro de 2020 Aceito em 15 de fevereiro de 2020 


\section{Abstract:}

The transnationalization of Candomblé to Portugal represents a strong process of religious reconfiguration that has been a matter of discussion in the anthropological literature. Despite the existence of a Candomblé reconfiguration amid its adoption in Portugal that demonstrates Candomblés foundational plasticity and the need of reconfiguration in a new social and cultural environment, this paper stresses the sociological phenomenon of conflict between local practitioners, presenting it as a structural element of the Portuguese Candomblé religiosity, which invokes the existence of constructing and reconstructing alliances based on the criteria of nationality, sexuality, and religious market demands.

Keywords: Candomblé, Portugal, Conflict, Religious Market.

\section{INTRODUÇÃO}

O estudo da transnacionalização das religiões afro-brasileiras para a Europa vem enfatizando, sobretudo, a capacidade plástica dessas religiões, evidenciando as dinâmicas híbridas e as "adaptações criativas" (DIAS, 2013) de religiões que necessitam dialogar com atavismos culturais do campo religioso de chegada. Bahia e Dantas (2018), seguindo o roteiro de outros trabalhos da primeira (BAHIA, 2014, 2015), refletem sobre os processos de acomodação do Candomblé na Alemanha, país onde o romantismo (literário) recuperou a relação do sujeito urbano com a Natureza. É por essa via, e pela via da corporalidade, que os alemães aderem ao Candomblé e à Umbanda. Conforme Bahia (2014), o limiar da participação é definido, contudo, quando o transe e o sacrifício animal entram na equação da espiritualidade. Nesses termos, percebemos, perfeitamente, a forma como a Nova Era opera na configuração das experiências e filiações religiosas. Com efeito, a aurora do multiculturalismo, do "desencantamento" weberiano e da secularização na Europa, trouxeram a busca por novas sensibilidades éticas, estéticas e espirituais. Essa nova espiritualidade almejada não demanda, necessariamente, por uma organização real, dogmas ou textos sagrados (SIQUEIRA, 2003), mas antes enfatiza a 
individuação da experiência, a livre-escolha (BERGER, 1992), a qual, não raras vezes, é temporária. Essa temporalidade e possibilidade de refiliação permanente entram em ação, no caso em referência, quando o Candomblé perde a sua dimensão "exótica" (PRANDI, 2004) e se revela real, i.e., quando o transe aparece e os ritos sacrificiais são demandados.

Apesar da natureza plástica permanecer, o caso do Candomblé em Portugal apresenta características diferenciadas do caso alemão. Em primeiro lugar não ocorreu a racionalização sociológica, mesmo tendo se dado a laicização do espaço público. A abertura democrática trazida pela "Revolução dos Cravos", em 1974, correspondeu a uma mudança profunda da sociedade portuguesa, depois de quatro décadas de ideologia rural, de atraso tecnológico e de subdesenvolvimento social. Em consequência dessa abertura e da leva de "retornados" (os portugueses que haviam partido para as colônias em África e que agora retornam ao país), a sociedade portuguesa foi conhecendo o multiculturalismo, dando origem, no campo religioso, ao que Teixeira (2013, p. 115) chama de "desfragmentação da unidade católica", responsável pelo surgimento de "novos itinerários para o sagrado" (MARGRY, 2008, p. 34). Não obstante a pluralização do campo religioso português, o catolicismo permaneceu como pano de fundo sociológico, ainda que segundo uma lógica de "pertencimento sem crença" (VILAÇA, 2013, p. 106).

Neste artigo pretendo seguir uma trilha diferente da apresentada pela literatura dedicada ao tema a qual enfatiza, essencialmente, os processos de adaptação simbólica e ritual de tais religiões à Portugal (PORDEUS JR., 1996, 2000, 2009; GUILLOT, 2009, 2010), enfocando os diálogos entre referenciais católicos e afro-brasileiros. Assim, pretendo explicitar a dimensão sociológica do Candomblé por via das relações entre membros da comunidade candomblecista, as quais assentam, sobretudo, numa lógica de conflito segundo três vetores: sexualidade, nacionalidade e mercado religioso; os quais, todavia, não se demarcam claramente.

Os dados aqui apresentados, são resultado de uma coleta informal dos mesmos, produto de uma exposição de longo-termo às religiões afro-brasileiras em Portugal, desde meados da década de 1990, em circunstância não-intencional de etnografia, uma vez que estava iniciando meu próprio trajeto como 
membro da religião, ao mesmo tempo que experienciava uma intenção de anotação rigorosa e científica do que ia observando.

Com efeito, a necessidade da produção deste trabalho resultou da evidência do fator "conflito" na estruturação das relações entre membros dos terreiros. Tal fenômeno vem sendo observado ao longo de um período quase ininterrupto de contato com o Candomblé em Portugal, que dista desde a já longínqua década de 1990, em que o número de terreiros no país era escasso, até ao presente ano de 2019.

Para efeitos de moldura teórica, conflito é aqui entendido como uma tipologia de relações, de caraterísticas dinâmica, politizada e polarizadora do campo religioso luso-afro-brasileiro. Seguindo o traçado por Gilberto Velho (2006, p. 246), conflito diz respeito a um "constante e ininterrupto processo de negociação da realidade, com idas e vindas, recuos e avanços, alianças sendo feitas e desfeitas, projetos adaptando-se e alterando-se, com transformações institucionais e individuais". Essa definição parece concordante com os cenários que serão explicitados adiante, aparecendo mais operatória para o estudo presente do que a definição de Zapparolli (2013) de uma incompatibilidade de valores, necessidades, opiniões ou desejos entre as partes intervenientes. Com efeito, uma vez que estamos operando num contexto específico, o do Candomblé, onde existe um conjunto de valores normativos e identificatórios, esse tipo de incompatibilidade não ocorre.

\section{OS PRIMEIROS SONS DO ATABAQUE EM TERRAS LUSAS}

Para se entender a acomodação das religiões afro-brasileiras em Portugal é preciso tomar contato com as dinâmicas religiosas de longo termo no país. Com efeito, o catolicismo lusitano, como registrava o espanhol Miguel de Unamuno (1985) no começo do séc. XX, sempre se animou debaixo da organização canônica por via de formas populares, através das práticas de devoção e pagamento de promessas (ex-votos) (CABRAL, 1984), e inúmeros especialistas, como "senhoras da virtude", "videntes", "curandeiras" e "curandeiros", entre outras denominações (CARVALHO, 1996). Essas práticas 
alternativas, muitas vezes tidas por subversivas, embora amplamente difundidas e procuradas (MARTINS, 1997; MONTENEGRO, 2005), foram importantes na constituição de um terreno fértil para outras soluções para os mesmos problemas: doenças do corpo e do espírito, mal de inveja, mau-olhado, entre outras. Tal como no Brasil, as religiões afro-brasileiras operam em Portugal ${ }^{3}$ segundo o princípio de "religiões de aflição" (SARAIVA, 2017), sendo buscadas nas soluções de problemas de ordem espiritual e física. Desse modo, tais religiões oferecem diferentes soluções para os mesmos problemas, introduzindo-se no país pela via do mercado religioso das aflições humanas e acomodando-se ao imaginário popular por via dos pontos de convergência de problemas para os quais oferecem outra tipologia de solução, e graças à plasticidade afro-brasileira, de forte expressão sincrética afro-católica. "Seu” Tranca-Ruas ${ }^{4}$ passa a competir com o Dr. Sousa Martins - entidade estudada por Tânia Welter (2007) e Iemanjá aparece como uma santa brasileira, conforme pude coletar junto de pessoas não ligadas às religiões afro-brasileiras, divindade cujo impacto sociológico Joana Bahia (2015) associa aos feitos marítimos portugueses. Convém, todavia, lembrar o efeito das telenovelas brasileiras no imaginário português sobre o Brasil (CUNHA, 2003) e a forma como elas introduziram a figura de Iemanjá nesse imaginário sobre o "exótico" religioso brasileiro.

A chegada das religiões afro-brasileiras a Portugal se dá em 25 de abril de 1974, data que marca o fim do regime ditatorial do Estado Novo e o advento da Democracia. Com o retorno dos portugueses que estavam nas antigas colônias e no Brasil, ocorre uma abertura dos horizontes culturais. Dentre aqueles que desembarcaram em Lisboa, agora com um novo aroma de liberdade, encontrava-se Virgínia Albuquerque, uma portuguesa que havia emigrado para o Rio de Janeiro em 1950, com a idade de catorze anos (PORDEUS JR., 2000).

\footnotetext{
No contexto português, a fronteira entre Umbanda e candombé não é facilmente traçável. Apesar de alguns terreiros praticarem exclusivamente Candomblé, a maioria dos terreiros que se reconhecem enquanto tal, praticam, igualmente, Umbanda, bem como terreiros de Umbanda se auto-classificam como de Candomblé. Do ponto de vista demográfico, a Umbanda é a religião com maior penetração, devido a facilidades linguísticas, mas também pela prática de consultas com as “entidades", motivo que leva a maioria dos terreiros de Candomblé a prestarem esse mesmo serviço.

4 Espírito da Umbanda, o Tranca-Ruas é um avatar de exú (espírito “da rua”, representante da "malandragem”) ligado à capacidade de "trancar" os caminhos dos inimigos.
} 
Virgínia, iniciou-se em 1960 na Umbanda e dezesseis anos depois fazia novamente a travessia atlântica em direção ao país de origem, trazendo consigo uma bagagem que mudaria a história do campo religioso português. A instalação do seu terreiro de Omolocô $\hat{o}^{5}$ é uma das primeiras etapas da abertura religiosa em Portugal, sendo pioneiro na instalação das religiões afro-brasileiras em território português. Tratouse, portanto, da primeira vaga de transnacionalização das religiões afro-brasileiras para Portugal. Depois dessa primeira etapa, ocorre um segundo movimento, ligado em particular aos portugueses, mas não apenas, que, tendo iniciado sua trajetória no terreiro de Mãe Virgínia, buscam as suas iniciações no Candomblé. Esse processo de migração interna foi notado por Prandi (1991) para São Paulo e Capone (2004) para o Rio de Janeiro, e diz respeito à busca por uma maior africanidade, ou seja, uma maior "autenticidade" religiosa. Foi nesse período que Albertina de Oyá (Maria Albertina Bernardo Gonçalves), que se havia iniciado na Umbanda Omolocô com Mãe Virgínia em 1979, parte, em 1986, rumo a São Paulo, onde se iniciaria no Candomblé com a célebre Mãe Olga do Alaketu, abrindo o seu terreiro em 1987 (BANDEIRA, 2009) ${ }^{6}$. Em torno dos anos de 1990 até ao começo do século XXI, um punhado de portugueses partiram para o Brasil para se iniciarem no Candomblé, em particular no terreiro Pilão de Prata, em Salvador. Esse momento configura uma segunda vaga do trânsito religioso candomblecista, a qual, todavia, poderia emoldurar-se numa primeira etapa: a da iniciativa portuguesa. Tal etapa, concentrada na agência portuguesa, constitui-se um caso particularmente interessante de incorporação rápida dos valores afro-religiosos e de iniciativa de transnacionalização, contrariando os processos comuns de expansão das religiões afro-brasileiras pela via migratória de brasileiros, como é o caso alemão. Assim, tanto a Umbanda quanto o Candomblé

\footnotetext{
Omolocô ou Omoloko; a sua classificação é difícil, porquanto tanto pode pertencer ao segmento do Candomblé "misto" quanto à Umbanda "traçada", uma vez que possui elementos de ambos. Há quem considere que o culto Omolocô está na base das ramificações mais africanizadas da Umbanda, uma vez que possui culto aos Orixás yorùbá e aos Inkices angola (SILVA, 1984). No entanto, em virtude da predominância do culto de caboclos e pretos-velhos (espíritos dos índios brasileiros e escravos africanos), apesar da prática de sacrifício animal e do culto aos Orixás e Inkices, o Omolocô é, de um modo abrangente, considerado como uma versão "africanizada" da Umbanda.

6 Capone (2004) nota que após iniciados no Candomblé, os sacerdotes umbandistas dão seguimento ao seu trajeto sacerdotal, agora no novo segmento afro-religioso, burlando, desse jeito, a lógica iniciática que decorre do estágio de noviço à maioridade.
} 
se instalam em Portugal pela mão de portugueses, sendo que no caso do Candomblé são portugueses que partem em busca da "autenticidade africana"”. Nesse período, o Candomblé tem um respaldo sociológico reduzido, permanecendo como religião de grande secretismo, sendo que o terreiro de Mãe Tina, o Ilê Omo Orixá Kuitichina Oba, aparece como referência, constituindo-se como o terreiro de Candomblé em Portugal por excelência.

A virada do milênio e as políticas de facilitação de imigração do governo português, associadas à proximidade linguística e cultural - que Padilha (2006) designa como uma imagem mental de velha mátria - trouxeram uma forte vaga migratória brasileira para o país. No quadro dessa vaga migratória surge a segunda etapa da instalação do Candomblé em Portugal, agora na vinda de brasileiros para o país. Tais sacerdotes podem ser classificados da seguinte forma: aqueles que vêm com o objetivo de encontrar trabalho noutras áreas do seu conhecimento (com destaque para a profissão de cabeleireiro), os que chegam procurando apresentar seus serviços religiosos por um período curto de tempo, alguns dos quais acabam ficando e instalando seus terreiros, os que vêm com a intenção de instalar seus terreiros, e por fim um alargado número de religiosos que se tornam sacerdotes em Portugal. Essa etapa é determinante para a consolidação de uma rede de terreiros, onde solidariedade migratória e concorrência mercadológica evidenciam a centralidade do fenômeno "conflito" como estruturante.

\section{O PRIMEIRO CASO DE CONFLITO}

Do ponto de vista da análise considero pertinente apresentar o primeiro caso conhecido, e realmente significativo, de conflito no quadro dos terreiros de Candomblé de Portugal, a partir do qual é possível traçar alguns dos eixos de abordagem deste estudo. O primeiro caso ocorreu no terreiro de Mãe Tina de Oyá.

\footnotetext{
A questão da autenticidade africana é fundacional nos estudos do Candomblé, e embora alguns autores posteriores novamente debatam o assunto, Capone (2004) resume perfeitamente o que está em causa nesse idioma diacrítico.
} 
Tal como dá conta Bandeira (2009), Mãe Tina recebe, em sua casa, em 1989, Nilsinho de Ibeji, filho biológico de Mãe Olga do Alaketu. Alguns relatos dão conta de que Nilsinho seria ogan ${ }^{8}$, outros de que seria Oluô ${ }^{9}$. No entanto, a narrativa dominante é que se trataria de um babalorixá, ou seja, pai de santo. Em 1996, Nilsinho abandona a casa de Tina, na sequência de uma série de conflitos pessoais entre ambos, nomeadamente ligados ao filho carnal da mãe de santo, o pai pequeno da casa, Mário Rui, que teria se envolvido numa relação com Nilsinho. Mário Rui viria a falecer com 22 anos de idade, falecimento do qual foi atribuída responsabilidade a Nilsinho, segundo rumores na época, com os quais tive contato.

Este é um primeiro capítulo de um processo intenso de conflitos que irão estruturar determinantemente o campo religioso candomblecista em Portugal. Com efeito, a saída de Nilsinho do terreiro de Tina, onde era peça determinante no cotidiano ritual, resultou numa desestruturação humana do terreiro, pois não apenas os filhos carnais de Mãe Tina o acompanharam, como grande parte dos chamados "filhos de santo" seguem o mesmo rumo. Esse episódio invoca o idioma da legitimidade/autenticidade, produzindo uma dinâmica sociológica de filiação e refiliação religiosa. Tanto a filiação quanto a legitimidade, a rigor, estão implicitamente relacionadas. Isto porque, a filiação de novos filhos de santo e a manutenção dos existentes depende de um permanente reconhecimento de legitimidade, tanto por parte daqueles quanto pelos demais sacerdotes do campo religioso. O abandono do terreiro de Mãe Tina, depois da disputa entre as duas figuras que assumiam a liderança, e o fato dos filhos biológicos e de santo terem seguido um dos intervenientes, permite compreender o impacto das disputas na consolidação de um grupo e a política da legitimidade. Como recorda Yvonne Maggie (1975), as disputas no interior dos terreiros são muito importantes no estabelecimento das dinâmicas internas de poder, cujas rupturas podem conter, inclusive, alterações de estatuto religioso, como relata Evangelista (2013). No caso que opôs Tina e Nilsinho, a atribuição de maior legitimidade (enquanto sinônimo de competência ritual)

\footnotetext{
8 Oficiante masculino que não entra em transe e que é responsável por aspetos rituais como a música e os sacrifícios.

9 Oluô ou Oluwo; cargo masculino destinado à prática oracular. Sinônimo ou similar ao babalaô.
} 
ao segundo resultou na dissolução das filiações e na constituição de uma nova filiação primária. $\mathrm{O}$ fato de Nilsinho ser brasileiro, baiano e filho biológico de Mãe Olga, revestiu-o de uma carga particular de autoridade-legitimidade que foi determinante no momento em que os filhos de santo do Ilê Omo Orixá Kuitichina Oba tiveram de optar por uma das filiações/fidelidades. A proximidade biológica e biográfica ao Alaketu, um dos mais respeitados terreiros do Brasil, constituiu fator decisório num campo religioso marcado pela ideologia da autenticidade.

\section{AUTENTICIDADE E CARREIRA}

No caso mencionado, foi possível apresentar como a legitimidade é um aspecto importante no quadro candomblecista, negociando filiações. Essa questão aporta a lutas de poder e a um cenário de política de autenticidade. De um modo geral, a política da autenticidade enquanto espaço de luta de poder, diz respeito a uma ideologia mais ou menos hegemônica de tradição, elaborada a partir dos padrões rituais, estéticos e éticos dos terreiros históricos de Salvador, constituindo-se um guião ortopráxico. Trata-se de uma ideologia que é descrita na literatura antropológica como "discurso de pureza (nagô)", a qual já foi devidamente debatida por diferentes autores (CAPONE, 2004; CASTILLO, 2008; DIAS, 2016; PARÉS, 2010). Conforme se encontra discutido em João Ferreira Dias (2016), a partir do estudo de caso do Candomblé em Uberaba, pequena cidade do triângulo mineiro, a política da autenticidade contém uma luta de poder evidente e que demanda pela permanente revitalização dessa autenticidade/legitimidade. Portanto, essa autenticidade/legitimidade não é um dado adquirido, um valor constante, mas precisa ser renovada pois está sempre sujeita a contestação. Trata-se do resultado do cruzamento entre academia e os terreiros, com uma interfertilização de agendas, bem como revela a capacidade de aglutinação da tríade Casa Branca-Gantois-Opô Afonjá (históricos terreiros nagô de Salvador) junto aos pesquisadores (CASTILLO, 2008). Tais terreiros configuram, portanto, territórios de tradição, ou seja, os lugares a partir do qual se mede e delimitam as fronteiras da práxis candomblecista nagô (ou ketu). Com efeito, a autenticidade constitui uma intenção de poder dos terreiros históricos, 
fixando a sua posição como lugares de produção de normatividade ética, estética e ritual (DIAS, 2016).

Ora, o processo de contestação de autenticidade resulta de dois fatores nem sempre coabitantes: o da noção de tradição, ligada à ideologia de "pureza", como um discurso de ortopraxia; e o do território da economia dos bens religiosos, ou dito de outra forma - o mercado religioso na sua mais clara feição capitalista. Prandi (2004) refere a entrada das religiões afro-brasileiras num contexto de competição entre elas, mas também com outros segmentos religiosos. Essa competição pela detenção da maior "clientela" possível não ocorre somente entre religiões. Na verdade, observando a dinâmica do campo afro-brasileiro, a competição interna é muito superior à competição frente outras religiões. É ela que alinha as dinâmicas, uma vez que a detenção de uma autenticidade religiosa implica em competição e hierarquização que se pretende traduzida em mais-valias de mercado, onde a economia dos bens religiosos dita que estes sejam transacionados não pelo seu valor efetivo (por se tratarem de bens simbólicos), mas pelo seu valor político-ideológico, muitas vezes o da autenticidade ou fidelidade à "tradição".

Ora, se para ter mais sucesso no mercado é preciso estar mais próximo das raízes, a legitimidade/autenticidade deve, então, ser buscada nos terreiros históricos de Salvador, em particular nos nagôs. No entanto, essa legitimidade é, também ela, contestável, porque a busca pela fidelidade é um trajeto que não tem fim. É essa a razão do sucesso do movimento de reafricanização no Brasil, que se reflete na busca por babalaôs cubanos e nigerianos, sacerdotes nigerianos que viajam ao Brasil, por viagens iniciáticas à Nigéria, e outras iniciativas de investidura de autenticidade, sempre em direção ao passado (CAPONE, 2004, 2011; LÉPINE, 2002). No campo candomblecista português, a realidade é diferenciada. Em primeiro, o fato da maioria dos primeiros sacerdotes estarem ainda vivos e da religião ter apenas três décadas de existência em Portugal faz com que o processo de consolidação no campo religioso português esteja ainda em curso. Em segundo, o vaivém entre o Brasil e Portugal, quer por parte de zeladores portugueses, quer pela parte de zeladores brasileiros, é permanente, reativando as redes de relações entre ambos países. Nesse sentido, a autenticidade é auferida 
pela proximidade a algum terreiro brasileiro e, como veremos a diante, pela nacionalidade.

A "troca de águas" (CAPONE, 2004) é uma das estratégias bem conhecidas para adquirir maior autenticidade, solucionar conflitos e burlar anteriores dependências na relação iniciador-iniciado. As "águas", na linguagem candomblecista, costumam dizer respeito às linhagens ou "nações" (COSTA LIMA, 1976), enquanto segmentos rituais, pelo que essa mudança ou "troca" invoca uma alteração mais profunda, relacionada ao modus operandi. No caso português, a questão das linhagens não se coloca. A ruptura dos vínculos iniciáticos é feita tendo em vista, majoritariamente, fatores de mercado. Em trabalho anterior (DIAS, 2018, p. 138), já havia referido que "outros aspetos mercadológicos e alojados às ambições de carreira são, também, evidenciados nesta dinâmica de troca de sacerdote", embora tenha remetido o assunto para discussão posterior. Ora, são tais termos que venho aqui enfocar. Seguindo a trilha histórica, sabemos - e a literatura dá conta desse fato - que a memória cultural portuguesa é polvilhada pelas imagens das curandeiras, videntes, médiuns, bruxas, e outras denominações, numa lógica que foge ao controle eclesiástico, muitas vezes questionando o poder do padre, onde o "dom" ${ }^{10}$ é idioma central. Das minhas experiências etnográficas, tanto em matéria de religiões afro-brasileiras, quanto de outras práticas, o uso do termo foi sendo recorrente, em diferentes contextos, como explicação para a ocorrência de certos fenômenos espirituais e justificativa para o exercício de práticas de cura, vidência e, ao caso, sacerdócio. A invocação da posse de um dom, i.e., de uma capacidade de servir como meio de comunicação entre os planos físico e espiritual, e de manipular elementos, legitima a prática do curandeirismo. Esse modelo explicativo-justificativo, cuja veracidade resulta do reconhecimento comunitário dos clientes, é transposto às religiões afro-brasileiras em Portugal, sem diferença entre Candomblé e Umbanda. Uma parte significativa dos iniciados e dos sacerdotes portugueses de tais religiões afirmam possuir um "dom", e que seria esse "dom" a razão de sua adesão religiosa. De um modo geral, uma parte considerável dos iniciados

\footnotetext{
${ }_{10}$ Para uma análise do "dom” no quadro do Candomblé ver Goldman (2012) e Sansi (2009).
} 
portugueses possui uma agenda própria, aquilo que anteriormente designei por "ambição de carreira", e que se traduz numa adesão a tais religiões com o intuito de abrirem seus próprios terreiros, ou, ao menos, seus espaços de atendimento ao público. Como exposto noutro trabalho (DIAS, 2018), no campo candomblecista português ocorrem inúmeras adaptações e inovações rituais, entre elas a comum percepção de que a iniciação licitaria a prática do sacerdócio. Apesar dessa ideia estar sendo desconstruída, a verdade é que, durante algum tempo, muitos terreiros foram abertos sob tal doutrina ad hoc, i.e., tal ideia se tornou um primado produzido das ocorrências, muito mais do que um postulado teológico que evidencie uma intenção de construção de um novo paradigma ortopráxico. Isto significa que na busca de uma oportunidade de carreira, por via de uma interpretação mercadológica da atividade sacerdotal, muitos iaôs, i.e. neófitos, acabaram produzindo uma reinterpretação da senioridade e do acesso ao sacerdócio, aplicando, mutatis mutandi, os princípios de carreira das práticas de curandeirismo, vidência e outras similares.

Há, portanto, uma identidade mercadológica no Candomblé português, que ao confluir com um mercado restrito e altamente competitivo, produz um terreno fértil para o conflito. Lembrando as palavras de Gilberto Velho (2006), ocorrem a feitura e a desagregação de alianças. Esse processo de reordenação da dinâmica social pela via do conflito é estruturante porque tais alianças são, regra-geral, filiações religiosas. Filhos de santo que abandonam o terreiro onde foram iniciados, passando para outros onde o novo zelador lhes garante o sacerdócio que o anterior lhes haveria negado, ou onde constroem novas teias de dependência, mas, acima de tudo, destroem a dependência face ao seu iniciador garantindo - desse modo, um sentido de proteção diante de eventuais "vinganças" espirituais, designadas, de forma geral, por "demanda”. Esse jogo de troca de filiações permite, com efeito, aceder a um sacerdócio que poderia não ser possível no terreiro de iniciação. No novo terreiro, o sujeito adquire um estatuto diferenciado, cuja adesão ao novo grupo pode gerar conflito com a lógica de poder ali estabelecida.

Além do fenômeno de independência e proteção no processo de "troca de águas", a filiação comporta a dimensão de autenticidade, como mencionado. 
Pai A., português, foi iniciado por Mãe Tina. Após a ocorrência de conflitos não revelados, mudou-se para o terreiro de Pai B., brasileiro. Uma nova série de conflitos fez com que regressasse ao terreiro de Mãe Tina, sob o pretexto de que o seu Orixá havia sido ali iniciado, no ketu, e não se dava bem com o xambá de Pai B. Todavia, a sua permanência no Ilê Omo Orixá Kuitichina Oba foi de curta duração. A fim de se libertar dos vínculos iniciáticos, Pai A. abandona o terreiro de Mãe Tina e inicia o seu trajeto de sacerdócio autonomamente. Esse processo de construção e desconstrução de vínculos, bem como a natureza conflitual e dramática do processo, foi por mim acompanhada. Algum tempo depois, se coloca sob a tutela de um pai de santo oriundo de São Paulo, o qual permanece em Portugal por um período alargado de tempo. Esta busca permanente de Pai A., revela não apenas a ocorrência de conflitos, mas como tais conflitos estão imbrincados numa procura por uma maior autenticidade, que se traduz por buscar uma filiação tida como superior. Esse imbricamento entre autenticidade, conflito e filiação, está presente na vida religiosa de Pai A. Recentemente, uma de suas filhas de santo mais antigas, portuguesa, entra em disputa com ele, e em decorrência desse conflito tem lugar um afastamento definitivo do terreiro, passando a se apresentar como ialorixá, e buscando uma nova filiação, agora com um jovem babalorixá de São Paulo, Pai C. Esse processo se torna recorrente em Portugal. As andanças de filiação, com abandonos constantes entre terreiros, com particular criação de novas filiações dentro do campo candomblecista português, são, igualmente, geradoras de conflitos entre sacerdotes, que se sentem desconsiderados, injustiçados e "traídos" - termo mais recorrente -, tanto pelos filhos de santo que os abandonam quanto pelos demais sacerdotes que os acolhem. A citada ialorixá portuguesa, doravante Mãe D., fez aliança com Pai E., um babalorixá português, ao qual recorria para conhecimento de preconceitos da religião, os quais não detinha, não obstante se assumir como sacerdotisa. No entanto, por razões de concorrência geográfica, a aliança entre os dois é desfeita, e ocorrências de maledicência tomam parte numa relação que se tornou de conflito. As trocas de acusações no Facebook sobem de tom com a entrada em cena de Pai C., o qual fez um vídeo em direto ("Live") para a mesma rede social, com 
várias acusações de caráter a Pai E. Este conflito triangular tornou-se mais evidente, muito recentemente, em virtude de uma filha de santo de Pai E. ter mudado para o terreiro de Pai C. Tais trocas de acusação são publicadas nos seus murais do Facebook, publicamente acessíveis. Assim, quando a "avamunha não bate", ou seja, quando a harmonia expressa durante as cerimónias públicas de Candomblé cessa, quando os atabaques já estão em silêncio, o som que percorre os terreiros é o do fuxico.

Em meio a esses processos de desfiliação e refiliação, o idioma de autenticidade é invocado como justificativa, desconsiderando o conflito e compondo, dessa forma, uma espécie de memória alternativa dos fatos. Desse modo, ao invés de se declarar a existência de desentendimentos, o que surge como narrativa é a presença de uma autenticidade conquistada por via da refiliação. Através desse novo vínculo, a pessoa encontra um pai ou mãe de santo "melhor", que "sabe mais", que detém, em suma, mais conhecimento e, assim, maior autenticidade. Esse trajeto em direção à autenticidade é muitas vezes feito para além das fronteiras portuguesas, em direção ao Rio de Janeiro, São Paulo e Bahia. Num quadro português de conflito entre agentes religiosos candomblecistas, a viagem ao Brasil permite, a dois tempos, escapar da teia de conflitos entre sacerdotes atuantes em Portugal, assim como adquirir maior autenticidade, uma vez que o Brasil possui dimensão referencial particular: uma idealização de autenticidade.

Dos casos conhecidos, a maioria dos portugueses que realizam a travessia atlântica pretendem instalar-se em Portugal como sacerdotes, abrindo suas casas de culto. Esse fenômeno enfatiza a dimensão mercadológica e de carreira que marca o Candomblé em Portugal, embora tal não seja um exclusivo português. Conforme Prandi (2001, p. 55):

Muitos que se iniciam hoje no Candomblé têm uma aspiração ocupacional muito clara: desejam ser pais e mães-de-santo, buscando nessa religião, como acontece nas outras, um meio de vida e uma oportunidade de ascensão social. Para esses, quanto mais cedo for alcançada a senioridade, melhor, não raro burlando a contagem dos sete anos. 
As palavras de Prandi (2001) respaldam no campo religioso afro-brasileiro em Portugal. Para uma parte significativa dos sacerdotes candomblecistas em Portugal, tanto portugueses quanto brasileiros, o acesso ao sacerdócio representa uma oportunidade de ascensão social e obtenção de uma renda econômica que de outra forma não teriam. Por essa razão, a facilidade no acesso à carreira sacerdotal é um aspecto determinante na hora de escolher onde se iniciar e quais filiações estabelecer. Quanto à “troca de águas", um dos aspectos negociados por estes agentes religiosos portugueses que partem para as mãos de sacerdotes brasileiros, quer em Portugal, quer no Brasil, é o da legitimação da posição sacerdotal. Ou seja, a refiliação é feita segundo os termos claros de que o novo zelador aceita a sua condição de sacerdote. Essa dimensão negocial comporta uma dimensão econômica, uma vez mais, dado que o novo zelador obterá (ou decorre a expectativa de que obtenha) uma contribuição monetária, quer pelo rito de aceitação de tutela (lavagem da cabeça com ervas sagradas, colocação da "mão" na cabeça como sinal de autoridade, e alimento aos Orixás do novo protegido), quer por atribuição da "cuia", a cabaça contendo objetos rituais e que simboliza a atribuição de estatuto sacerdotal, designada, geralmente, por deká. Através dessa aritmética de possibilidades e negociações, tais agentes religiosos portugueses adquirem o seu quinhão de autenticidade/legimitidade.

Não obstante o recurso de estratégias de refiliação, a legitimidade é sempre contestável. A refiliação tende a ser contestada pelos demais sacerdotes como uma estratégia mercadológica, não encontrando reconhecimento no campo religioso afro-brasileiro em Portugal.

\section{SEXUALIDADE, NACIONALIDADE E MERCADO RELIGIOSO}

Tendo procurado evidenciar o papel da autenticidade no quadro candomblecista português, em particular diante do fenômeno social do conflito e da forma como a autenticidade é invocada como processo de velo, configura-se oportuno, nesse momento, adentrar na temática da sexualidade 
e da nacionalidade como produtores de aliança e conflitos no seio do mercado religioso.

A heteronorma social (ROSENEIL, 2006) ${ }^{11}$ é questionada no seio do Candomblé, embora a circunstância favorável à presença homossexual não tenha sido nem seja, ainda, uma questão resolvida (LANDES, 1947; MATORY, 2008; RIOS, 2012). Ao enfatizar o homossexual efeminado, ou dito de outro modo, ao elaborar sobre gênero, Landes ressalta a inscrição dramática do Candomblé no mercado religioso, onde o idioma da autenticidade reclamava pela coincidência entre o padrão social heteronormativo e o desempenho do papel de gênero feminino e de liderança sacerdotal como um exclusivo das mulheres. Não obstante essa visão, que tem uma agenda por detrás, e que Matory (2008) denuncia, a realidade do culto aos Orixás apresenta uma complexidade maior, que questiona as fronteiras rígidas estabelecidas pela normatividade social. A iniciação, por exemplo, representa a transformação dos papéis, uma vez que um homem iniciado para um Orixá masculino desempenha o papel de noiva (iaô) da divindade, razão pela qual Santos (2008) afirma que o iniciado, em transe, assume o papel de vasilha da divindade, sendo, portanto, possuído e, assim, desempenhando um papel feminino. Tal como o sacerdote de Xangô, em Oyó, traja de mulher (MATORY, 1994, 2005), representando a esposa da divindade, também Castillo e Parés (2007) recuperam relatos sobre o período da formação da Casa Branca, em que um negro chamado Thomé aparece trajado de mulher durante um ritual. Edison Carneiro, que mais tarde viria a assumir o discurso da heteronorma de Landes, dava conta, em trabalhos anteriores, do costume frequente dos homens iniciados para o transe ritual (élégun) trajarem como mulheres (apud MATORY, 2008). No seio desta multiplicidade de papéis, compreende-se a afirmação de Birman (1995) de que os Orixás desempenham um papel de referência pensante da sexualidade dos

\footnotetext{
${ }^{11}$ Todavia, como nos informa Miguel Vale de Almeida (1996, s/p.), "a masculinidade não éa mera formulação cultural de um dado natural; e que a sua definição, aquisição e manutenção constitui um processo social frágil, vigiado, auto-vigiado e disputado. Os significados circu- lantes sobre género, herdados do passado, assentam numa simbólica de divisão do mundo em masculino e feminino, constituindo-se esta numa dicotomia fundamental e princípio classificatório. Isto é visível em múltiplos aspectos etnográficos, como seja, por exemplo, a atribuição de género a actividades, objectos, acções, emoções, espaços da casa, espaços da aldeia etc".
} 
sujeitos, argumento que Teixeira (1987) recupera a partir da fala de membros dos terreiros, que justificam sua sexualidade pela ambivalência dos Orixás aos quais estão consagrados.

Não obstante a dinâmica do campo religioso afro-brasileiro, no Brasil, ditar um diálogo nem sempre fácil entre as múltiplas representações de gênero existentes no Candomblé e a heteronormatividade da sociedade, no caso do Candomblé português ocorre uma rasgadura dos sentidos de representação de gênero. Recordando Joana Bahia (2015 p. 122) a propósito dos terreiros portuenses: "prostitutas, travestis e michês, transitam como membros das suas famílias de santo, participando ativamente da vida ritual. Clientes, donos de casa de prostituição, muitos trazidos pelos brasileiros, solicitam proteção de e cuidado com os seus negócios". Esse fenômeno, ainda que complexo pois como Bahia (2015, p. 122) salienta, alguns pais de santo brasileiros preferem não ter muitos filhos de santo brasileiros, "que tornariam seu axé um axé com menos respeito, pelo excesso de homossexuais, que se comportariam como "meninas" - é parte significativa da identidade candomblecista portuguesa e ajuda a perceber uma espécie de paisagem social instituída que permite explicitar a experiência de rasgadura dos sentidos heteronormativados. Se alguns pais de santo preferem manter o terreiro segundo determinados padrões, a verdade é que tantos esses quanto outros, fazem uso de sua identidade sexual no jogo da representação do Candomblé em Portugal, através da exteriorização estética de um padrão feminino de ser pai de santo, com os torsos (ojá) e o pano da costa ${ }^{12}$. Ora, tal fenômeno de hiperestetização (DIAS, 2016), que no Brasil é invocado como "abusivo", no contexto candomblecista português opera no sentido de produzir um estereótipo de sacerdote, autenticando-o a partir do seu viés exotizado. Dessa forma, o estereótipo de sacerdote do Candomblé, em Portugal, é o do homem, homossexual, brasileiro e esteticamente hiperbolizado. Por outras palavras, o cânone é o de Joãozinho da Gomeia (CHEVITARESE; PEREIRA, 2016; FERREIRA, 2016; GAMA, 2014),

\footnotetext{
2 Atado ao peito, o pano da costa é um adereço exclusivamente feminino, cobrindo o peito e o sexo das mulheres. A utilização desta indumentária em homens é considerada violação dos códigos estéticos, razão pela qual a Casa de Oxumarê, terreiro baiano, emitiu um comunicado em sua página no Facebook proibindo os homens de entrarem com pano da costa e torso naquele espaço de culto.
} 
invertendo a lógica discursiva de Ruth Landes (1947) acerca da "cidade das mulheres".

Esse fenômeno de exotização estética e estereotipação, que funciona como reforço positivo no quadro do mercado religioso, acompanha um processo, estudado por Igor Machado (2016), de exotização e inversão racial ligadas à emigração brasileira para Portugal. Com efeito, a trama do conflito é feita no tear da solidariedade migratória, cujos fios grossos da concorrência mercadológica são determinantes na produção de um tapete onde se entrelaçam sexualidade, nacionalidade e mercado.

Ora, numa primeira fase, a confluência migratória permite que os candomblecistas brasileiros se associem, valorizando, em primeiro lugar, o fator nacionalidade na constituição de uma rede de relações e alianças. A partilha de um quadro de referências culturais é um facilitador de agremiação num contexto migratório. A consequência dessa consociação é a formação de uma identidade contrastativa face aos candomblecistas portugueses, numa lógica que continua sentidos maiores da emigração brasileira, pois, como nota Machado (2017), os brasileiros emigrados para a cidade do Porto tendem a torcer por um time de Lisboa, afirmando a sua identidade por oposição. Ora, uma vez que a quase totalidade desses sacerdotes brasileiros são homossexuais, a agremiação opera em três níveis: nacionalidade, religião e a sexualidade. O sentido de pertença é, então, vincado num cenário migratório.

Não obstante a existência de uma rede de solidariedades entre eles, com a participação nas festividades daqueles que conseguem instalar suas casas de culto (muitas vezes armazéns ou garagens reconvertidas em terreiros), o fato do campo religioso onde o Candomblé opera ser diminuto e, por consequência, fortemente competitivo, o sentido mercadológico vem à tona produzindo um contexto de permanente conflito. Através do ejó, o fuxico (BRAGA, 1998), acontece tanto uma manutenção da tradição por via do questionamento de práticas de outrem, como uma descredibilização dos demais, permitindo se autenticar diante de potenciais membros de seu terreiro ou clientes. Nos momentos de paragem, no decurso de cerimónias públicas de Candomblé, ou seja, quando a "avamunha não toca”, é comum alguns destes sacerdotes distribuírem o seu 
contato entre algumas pessoas da assistência, depois de uma breve conversa sobre o problema que as apoquenta.

Um caso exemplar de como a nacionalidade não garante a solidariedade de modo absoluto, em meio à dimensão econômica, foi o conflito entre um pai de santo e sua mãe de santo, ambos oriundos de São Paulo e atuantes na região designada por "Grande Porto". Em decorrência de uma cliente (supostamente uma pessoa abastada) que o primeiro teria "roubado" de sua mãe de santo, surgiram (ou "vazaram", na linguagem corrente) inúmeros áudios no WhatsApp, aos quais tive acesso, com troca de acusações e denúncia de fraudes mútuas. A escalada de acusações culminou num evento de violência física entre ambos.

Mas se a nacionalidade opera num sentido de produzir coesão social entre candomblecistas brasileiros, pelo menos numa fase inicial, um outro elemento é determinante na cooperação entre sacerdotes e na relação entre candomblecistas brasileiros e portugueses: a sexualidade. Como visto, candomblecistas brasileiros fazem uso e promovem um estereótipo de pai de santo exotizado, que subverte a heteronorma, gerando uma justaposição entre fenômenos tidos por "subversivos": a homossexualidade e o campo das religiões não-abraâmicas. Ora, é precisamente no cruzamento entre dimensões subversivas que o exótico do pai de santo, homossexual, efeminado, brasileiro, tem um valor inverso, operando como marca de autenticação. Assim, ao se aproximarem, por via de teias de solidariedade, origina-se um nicho sociológico no campo candomblecista português que forma uma estruturação em castas, na qual a casta superior é composta pelos sacerdotes brasileiros homossexuais e travestis, seguidos pelos sacerdotes brasileiros heterossexuais, após os quais vêm os sacerdotes portugueses homossexuais e, por fim, os heterossexuais portugueses, com enfoque para as mulheres. De um modo geral, as mulheres representam um nicho desconsiderado no seio da formação das alianças, uma vez que se afastam do estereótipo idealizado, em particular as mulheres portuguesas heterossexuais. Os pais de santo portugueses, em particular os homossexuais, tendem a circular no seio da casta superior, sem, contudo, serem totalmente incluídos, e sendo o principal objeto de ejó dos demais. No entanto, nem a partilha da nacionalidade nem da sexualidade ou do gênero chegam 
para produzir uma paz kantiana no campo candomblecista português, inclusive entre brasileiros. Isto porque, como mencionado, a dimensão mercadológica impera, num contexto de mercado concorrencial, restrito e de fluxo migratório permanente. Na hora de obter renda, ter a mesma nacionalidade ou orientação sexual não chega para impedir situações de conflito. A conquista de um espaço no mercado religioso obriga a estratégias de comunicação que vão de anúncios em jornais até ao Facebook, com ofertas de serviços para todos os fins, cuja linguagem se cruza com práticas históricas portuguesas de curandeirismo, mas que concorre, igualmente, por vezes característica por característica, com as ofertas de religiosos islâmicos africanos, os "professores" e "mestres" que aparecem nos jornais diários de maior tiragem.

\section{CONCLUSÃO}

O espaço exíguo não permite uma exposição demorada das mais variadas ocorrências de conflito que estruturam, indelevelmente, o campo candomblecista português. Não obstante, foram apresentadas algumas das ocorrências mais significativas e que permitem elencar a ideia de que é o conflito o aspecto estruturante do Candomblé em terras lusas, a partir do qual são estabelecidas as alianças.

Apesar de se produzirem alianças com base na nacionalidade e na orientação sexual, em primeiro lugar entre religiosos brasileiros e, posteriormente, com religiosos portugueses, a verdade é que a afirmação de uma agência sacerdotal, aliada a características do mercado religioso não-cristão em Portugal - diminuto e marcado por um número significativo de ofertas, que vão do curandeirismo à vidência, passando pelas experiências Nova Era, pela Umbanda e pelo Candomblé - produz uma circunstância onde a renda é absolutamente necessária, sendo que na luta pela conquista de um lugar de destaque, captando o maior número de fiéis e clientes, o questionamento da autenticidade, o conflito verbal e físico, e a dissolução de alianças, formam um jogo intrincado onde a convivência é apenas aparentemente pacífica. 
Nesse jogo de forças, sacerdotes portugueses são, invariavelmente, desclassificados no seio de uma sociedade de castas, de cujo topo mais se afastam quanto mais distam do estereótipo constituído: pai de santo (homem), brasileiro, homossexual, esteticamente exotizado-efeminado. A autenticidade dos sacerdotes portugueses é publicamente questionada, desde logo, pelo fator nacionalidade. Não obstante terem sido iniciados no Brasil, eles representam a oposição com a qual os primeiros concorrem, apesar de, posteriormente, acabarem concorrendo entre si, produzindo, eventos de conflito constantes. Mesmo no caso em que, por sua orientação sexual, é permitido aos pais de santo portugueses participar do grupo, jamais são inteiramente integrados, sem a ocorrência de um caudal de fuxico. Nos termos vigentes, sacerdotes candomblecistas portugueses experienciam uma inversão de circunstâncias - no quadro de um território imaginário, o do Candomblé, eles se tornam estrangeiros em seu próprio país de nascimento.

A forma como operam as inovações rituais no Candomblé em Portugal (DIAS, 2018, 2019) explicita a inexistência de um discurso verdadeiramente estruturante de ortopraxia. Os debates circunstanciais em torno do modus operandi nãopretendem tanto "segurar as pontas" da "tradição" quanto produzirem a autodemarcação no mercado. Uma vez que é no tear do capitalismo religioso que a ação pública dos candomblecistas se expressa, é por causa do mercado concorrencial que o conflito se operacionaliza. Isto é tão válido para os sacerdotes já instalados, e na relação de aliança e oposição que estabelecem entre si, quanto para os membros das suas comunidades que, por via da peneira cultural das práticas não-eclesiásticas de cura e vidência, possuem uma agenda própria que se superioriza à agenda coletiva do terreiro. Por tais razões, desse último aspecto derivam eventos de conflito entre o sujeito-aspirante a sacerdote (que vê no sacerdócio uma fonte estável de renda e eventual ascensão social) e o seu iniciador, resultando daí novas filiações.

Quer isto dizer que se o fuxico pretende assegurar as fronteiras da ortopraxia candomblecista no Brasil, e na interseção com os discursos de "pureza" manter um ideal de "tradição", tornando-se um elemento estruturante do campo afro-brasileiro no país, no caso português a situação é diferenciada. Mais do que o ejó, é o conflito declarado que assegura a dinâmica do campo candomblecista português, através 
das alianças feitas e desfeitas, das refiliações, da participação e rejeição geradas pela nacionalidade e pela sexualidade. O Candomblé em Portugal não é apenas território do "diz-que-me-disse", mas do conflito aberto, verbal e por vezes físico, da acusação clara e direta, do "vale-tudo" na afirmação de uma posição no mercado concorrencial. Num mercado diminuto, onde a Umbanda possui maior implementação (SARAIVA, 2011), não basta corresponder ao estereótipo exotizado de sacerdócio, é preciso ir buscar filhos de santo e clientes na casa do aliado-concorrente. Nada é mais problemático para um sacerdote do que se ver na obrigação de receber em sua casa, nas cerimónias públicas, outros sacerdotes. Se a etiqueta e a aparência de solidariedade e aliança a tal obrigam, não é menos evidente que essa situação representa um perigo no contexto do mercado, pois é ali, em sua casa, que ele oferece palco para as performances artísticas dos demais sacerdotes, que invariavelmente tendem a procurar se destacar dos seus anfitriões, pela sua aparência, mas também pelos trejeitos de rosto que evidenciam uma rejeição do ritual, e a oportunidade de mostrarem sua sabedoria por meio de uma ou outra cantiga litúrgica. Não raras vezes, os intervalos entre a ação ritual servem para encetar contatos com potenciais clientes. Alguns sacerdotes menos contidos, chegam a convidar publicamente filhos de santo e clientes do anfitrião para a sua casa.

Assim, quando a avamunha não bate e não se escuta "Ogum Ajô ${ }^{13}$ ", o Candomblé em Portugal está sendo animado pelas tramas do conflito estruturante. É o tear do mercado religioso tecendo o campo candomblecista português com os fios do fuxico, da acusação, da disputa, da violência verbal e física, da descredibilização, da feitura e quebra de alianças.

\section{REFERÊNCIAS BIBLIOGRÁFICAS}

1. ALMEIDA, Miguel Vale de. Género, masculinidade e poder. Revendo um caso do Sul de Portugal. Anuário Antropológico, Brasília, v. 95, p. 161-190, 1996. Disponível em: http://bit.ly/32LtPu1. Acesso em: 28 out. 2019.

\footnotetext{
${ }^{13}$ Cantiga que inicia o xirê e que é entendida como um convite à harmonia.
} 
2. BAHIA, Joana. Under the Berlin sky. Candomblé on German shores. Vibrant, Brasília, v. 11, n. 2, p. 327-370, 2014.

3. BAHIA, Joana. Exu na mouraria: a transnacionalização das religiões afro-brasileiras e suas adaptações, trocas e proximidade com o contexto português. Métis, Caxias do Sul, v. 14, n. 28, p. 111-131, 2015.

4. BAHIA, Joana; DANTAS, Caroline Moreira Vieira. Música, corporalidade e recriação diaspórica no Candomblé na Alemanha. Ciências Sociais e Religião, Porto Alegre, v. 20, n. 28, p. 82-98, 2018.

5. BANDEIRA, Luiz Cláudio. Entidades africanas em "troca de águas": diásporas religiosas desde o Ceará. 2009. Dissertação (Mestrado em História Social) - Pontifícia Universidade Católica de São Paulo, São Paulo, 2009.

6. BERGER, Peter. A far glory: the quest for faith in an age of credulity. New York: Free Press, 1992.

7. BIRMAN, Patrícia. Fazer estilo criando gêneros: possessão e diferenças de gênero em terreiros de Umbanda e Candomblé no Rio de Janeiro. Rio de Janeiro: Relume-Dumará, 1995.

8. BRAGA, Julio Santana. Fuxico de Candomblé: estudos afro-brasileiros. Feira de Santana: Ed. UEFS, 1998.

9. CABRAL, João de Pina. O pagamento do santo: uma tipologia interpretativa dos ex-votos no contexto sócio-cultural do Noroeste português. Studium Generale, Porto, n. 6, p. 97-112, 1984.

10. CAPONE, Stefania. A busca da África no Candomblé. Rio de Janeiro: Pallas, 2004.

11. CAPONE, Stefania. O pai-de-santo e o babalaô: interação religiosa e rearranjos rituais na religião dos orishas. Revista Pós Ciências Sociais, São Luís, v. 8, n. 16, p. 107-128, 2011.

12. CARVALHO, António Maria Romeiro. A “curandeira”, a religião e a medicina na cultura popular. In: CONGRESSO PORTUGUÊS DE SOCIOLOGIA, 3., 1996, São Paulo. Anais [...]. Lisboa: Associação Portuguesa de Sociologia: Celta, 1996. p. 1-11. Disponível em: http://bit.ly/2woNooU. Acesso em: 30 out. 2019

13. CASTILLO, Lisa Earl; PARÉS, Luís Nicolau. Marcelina da Silva e seu mundo: novos dados para uma historiografia do Candomblé ketu. Afro-Ásia, Salvador, n. 36, p. 111-151, 2007.

14. CASTILLO, Lisa Earl. Entre a oralidade e a escrita: a etnografia nos Candomblés da Bahia. Salvador: Edufba, 2008.

15. CHEVITARESE, André Leonardo; PEREIRA, Rodrigo. O desvelar do Candomblé: a trajetória de Joãozinho da Gomeia como meio de afirmação dos cultos afro-brasileiros 
no Rio de Janeiro. Revista Brasileira de História das Religiões, Maringá, v. 9, n. 26, p. 43-65, 2016.

16. CUNHA, Isabel Ferin. As telenovelas brasileiras em Portugal. Biblioteca On-line de Ciências da Comunicação, [s. l.], 2013. Disponível em: http://bit.ly/2VENcDS. Acesso em: 30 de out. 2019.

17. DIAS, João Ferreira. "Em Roma sê romano": o Candomblé como adaptação criativa e hibridismo, nas origens e no séc. XXI: Bahia, Lisboa e Berlim. Revista Lusófona de Ciência das Religiões, Lisboa, ano 12, n. 18/19, p. 205-216, 2013.

18. DIAS, João Ferreira. “A África é aqui, no terreiro”: horizontes nostálgicos, sentidos da África e outros lugares no Candomblé (jeje-nagô) de Salvador e Uberaba. 2016. Tese (Doutorado em Estudos Africanos) - Instituto Universitário de Lisboa, Lisboa, 2016.

19. DIAS, João Ferreira. Outros como nós: sexualidade, nacionalidade e conflito no Candomblé em Portugal. Lusotopie, Provença, v. 17, n. 1, p. 136-158, 2018.

20. DIAS, João Ferreira. Candomblé das barreiras: análise de um terreiro reafricanizado. Rever, São Paulo, v. 19, n. 3, p. 117-135, 2019.

21. EVANGELISTA, Daniele Ferreira. Emoção não é coisa de Equede: mudança de status e relações de poder no Candomblé. Revista Intratextos, Rio de Janeiro, v. 4, n. 1, p. 93-106, 2013.

22. FERREIRA, Thiago Almeida. João da Goméia: transgressões e identidades de gênero no Candomblé. 2016. Trabalho de Conclusão de Curso (Graduação em História) - Universidade de Brasília, Brasília, DF, 2016 Disponível em: http://bit.ly/3apzt83. Acesso em: 29 out. 2019.

23. GAMA, Elizabeth Castelano. Mulato, homossexual e macumbeiro: que rei é este? Trajetória de Joãozinho da Gomeia (1941-1971). Duque de Caxias: APPH-CLIO, 2014.

24. GOLDMAN, Márcio. O dom e a iniciação revisitados: o dado e o feito em religiões de matriz africana no Brasil. Mana, Rio de Janeiro, v. 18, n. 2, p. 269-288, 2012.

25. GUILLOT, Maia. Du mythe del'unitéluso-afro-brésilienne: le candomblé etl'Umbanda au Portugal. Lusotopie, Provença, v. 16, n. 2, p. 205-219, 2009.

26. GUILLOT, Maia. "Axé Ilê Portugal”: parcours migratoires et religions afro- brésiliennes au Portugal. Autrepart, [s. l.], v. 56, n. 4, p. 57-74, 2010.

27. LANDES, Ruth. The city of Women. Albuquerque: University of New Mexico Press, 1947.

28. LÉPINE, Claude. O Candomblé "africanizado" no campo religioso paulistano. Cadernos CERU, São Paulo, série 2, n. 13, p. 173-191, 2002.

29. LIMA, Vivaldo Costa. O conceito de nação nos Candomblés da Bahia. Afro-Ásia, Salvador, n. 12, p. 65-89, 1976. 
30. MACHADO, Igor José de Reno. Imigração em Portugal, Estudos Avançados, São Paulo, v. 20, n. 57, p. 119-135, 2016.

31. MACHADO, Igor José de Reno. Reflexões sobre a imigração brasileira em Portugal. Nuevo mundo, mundos nuevos, Paris, n. 7, 2017. Disponível em: http://bit.ly/3cspdNZ. Acesso em: 30 out. 2019.

32. MARGRY, Peter Jan (ed.). Shrines and pilgrimage in the modern world: new itineraries into the sacred. Amsterdam: Amsterdam University Press, 2008.

33. MARTINS, José Garrucho. As bruxas e o transe: dos nomes às práticas. Vila Nova de Gaia: Estratégias Criativas, 1997.

34. MATORY, James Lorand. Sex and the empire that is no more: gender and the politics of metaphor in oyo yoruba religion. Minneapolis: Minnesota University Press, 1994.

35. MATORY, James Lorand. Black Atlantic religion: tradition, transnationalism and matriarchy in the afro-brazilian candomblé. Princeton: Princeton University Press, 2005.

36. MATORY, James Lorand. Feminismo, nacionalismo, e a luta pelo significado do adé no Candomblé: ou, como Edison Carneiro e Ruth Landes inverteram o curso da história. Revista de Antropologia, São Paulo, v. 51, n. 1, p. 107-121, 2008.

37. MONTENEGRO, Miguel. Les bruxos: des thérapeutes traditionnels et leur clientèle au Portugal. Paris: L'Harmattan, 2005.

38. PARÉS, Luís Nicolau. O mundo Atlântico e a constituição da hegemonia nagô no Candomblé baiano. Esboços: histórias em contextos globais, Florianópolis, v. 17, n. 23, p. 165-186, 2010.

39. PORDEUS JR., Ismael. Lisboa de caso com a Umbanda, Revista USP, São Paulo, n. 31, p. 90-103, 1996.

40. PORDEUS JR., Ismael. Uma casa luso-afro-brasileira com certeza: emigrações e metamorfoses da Umbanda em Portugal. São Paulo: Terceira Margem, 2000.

41. PORDEUS JR., Ismael. Portugal em transe. Lisboa: Imprensa de Ciências Sociais, 2009.

42. PRANDI, Reginaldo. Os Candomblés de São Paulo. São Paulo: Hucitec: Edusp, 1991.

43. PRANDI, Reginaldo. Candomblé e o tempo: concepções de tempo, saber e autoridade da África para as religiões afro-brasileiras. Revista Brasileira de Ciências Sociais, Fortaleza, v. 16, n. 47, p. 43-58, 2001.

44. PRANDI, Reginaldo. O Brasil com axé: Candomblé e Umbanda no mercado religioso. Estudos avançados, São Paulo, v. 18, n. 52, p. 223-238, 2004.

45. RIOS, Luís Filipe. O paradoxo dos prazeres: trabalho, homossexualidade e estilos de ser homem no Candomblé queto fluminense. Etnográfica, Lisboa v. 16, n. 1, p. 53-74, 2012. 
46. ROSENEIL, Sasha. Viver e amar para lá da heteronorma: uma análise queer das relações pessoais no século XXI. Revista crítica de ciências sociais, Coimbra, n. 76, p. 33-51, 2006.

47. SANSI, Roger. "Fazer o santo": dom, iniciação e historicidade nas religiões afro-brasileiras. Análise Social, Lisboa, v. 44, p. 139-160, 2009.

48. SANTOS, Milton Silva. Sexo, gênero e homossexualidade: o que diz o povo-de-santo paulista? Horizonte, Belo Horizonte, v. 6, n. 12, p. 145-156, 2008.

49. SARAIVA, Clara. Energias e curas: a Umbanda em Portugal. Revista Pós Ciências Sociais, São Luís, v. 8, n. 16, p. 55-76, 2011.

50. SARAIVA, Clara. Orixás across the Atlantic: the diaspora of afro-brazilian religions in europe. In: SCHMIDT, Bettina; ENGLER, Steven (org.). Handbook of contemporary religions in Brazil. Leiden: Brill, 2017. p. 320-332.

51. SILVA, Ornato José da. Culto Omolokô: os filhos de terreiro. Rio de Janeiro: Rabaço, 1984.

52. SIQUEIRA, Deis. A labiríntica busca religiosa na atualidade: crenças e práticas místicoesotéricas na capital do Brasil. In: LIMA, Ricardo Barbosa de; SIQUEIRA, Deis. Sociologia das adesões: novas religiosidades e a busca místico-esotérica na capital do Brasil. Rio de Janeiro: Garamond, 2003. p. 25-64.

53. TEIXEIRA, Alfredo. A eclesiosfera católica: pertença diferenciada. Didaskalia, Lisboa, v. 43, n. 1-2, p. 115-205, 2013.

54. TEIXEIRA, Maria Lina Leão. Lorogun: identidades sexuais e poder no Candomblé. In: MOURA, Carlos Eugênio (org.). Candomblé: desvendando identidades. Rio de Janeiro: EMW, 1987. p. 33-52.

55. UNAMUNO, Miguel de. Las animas del purgatorio en Portugal. In: DÍOS, M. (ed.), Escritos de Unamuno sobre Portugal. Paris: Calouste Gulbenkian. 1985. p. 144-149.

56. VELHO, Gilberto. Patrimônio, negociação e conflito, Mana, Rio de Janeiro, v. 12, n. 1, p. 237-248, 2006.

57. VILAÇA, Helena. Novas paisagens religiosas em Portugal: do centro às margens. Didaskalia, Lisboa v. 43, n. 2, p. 81-114, 2013.

58. WELTER, Tânia. Do curador ao santo: aproximações entre os processos de consagração de Dr. Sousa Martins, Santa da Ladeira e São João Maria Agostinho. Lusitania Sacra, Lisboa, 2. série, n. 19-20, p. 457-469, 2007.

59. ZAPPAROLLI, Célia Regina. Mediação de conflitos de gênero e família, em contextos de violência e crimes processados pelas Leis $n^{\text {os }}$ 11.340/2006 e 9.099/1995. In: SILVA, Luciana Aboim Machado Gonçalves da (org.). Mediação de conflitos. São Paulo: Atlas, 2013. p. 181-216. 